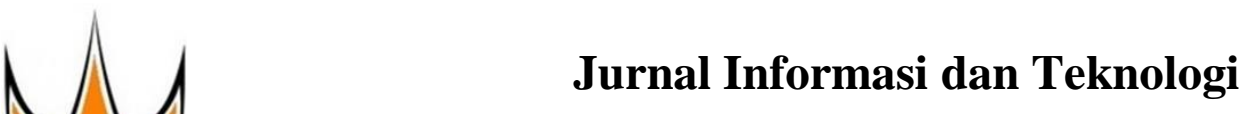

http://www.jidt.org

2022 Vol. 4 No. $1 \quad$ Hal: 46-51

e-ISSN: 2714-9730

\title{
Metode Vikor dalam Meningkatkan Kualitas Pembelajaran Terhadap Pemilihan Studi Club
}

\author{
Junaidi $^{1 \otimes}$ \\ ${ }^{1}$ Sekolah Tinggi Manajemen Informatika dan Komputer Royal \\ junaidijuna993@gmai 1.com
}

\begin{abstract}
Club studies are more non-formal learning methods and emphasize the participation of members/participants. In club studies, students get more roles than in class lectures, so club studies can be used as a companion method to increase student insight. Club studies are also one of the alternative learning methods designed to improve student competence by emphasizing the active participation of students. By participating in the study club, students have the ability to increase student scores compared to those who do not participate in the study club, so there is a difference between students who take part in the study club and those who do not take part in the study club. Student competence is very necessary, especially in the era of global competition. To find student talent in determining the selection of club studies as an alternative method of learning level in order to improve student competence and improve the quality of learning with the best graduates. Based on the analysis of improving the quality of learning in students against the selection of club studies with several criteria that can be taken from the students themselves, the assessment consists of the value of supporting courses, attendance values of supporting courses, practical test scores and interests. From the various criteria that students have, from this it can provide a determination in the selection of club studies according to the results of the criteria values owned by students.
\end{abstract}

Keywords: Study Clube, SPK, Stmik Royal, VIKOR, Students.

\begin{abstract}
Abstrak
Studi Club metode pembelajaran yang lebih bersifat non formal dan menekankan pada partisipasi anggota/peserta. Dalam studiclub mahasiswa mendapatkan peran yang lebih banyak dibandingkan dengan kuliah dikelas sehingga studi club dapat dijadikan salah satu metode pendamping untuk meningkatkan wawasan mahasiswa. Studi club juga sebagai salah satu alternative metode pembelajaran dirancang untuk meningkatkan kompetensi mahasiswa dengan menekankan partisipasi aktif dari mahasiswa. Dengan mengikuti study clube mahasiswa memiliki kemampuan dalam meningkatkan nilai mahasiswa dibandingkan dengan yang tidak mengikuti study clube, maka ada perbedaan antara mahasiswa yang mengikuti studi club dan yang tidak mengikuti studi club.kompetensi mahasiswa sangat diperlukan apalagi pada era pesaingan global. Untuk menemukan bakat mahasiswa dalam menentukan pemilihan studi club sebagai suatu alternative metode tingkat belajar dalam rangka meningkatkan kompetensi mahasiswa dan meningkatkan mutu belajar dengan lulusan terbaik. Berdasarkan analisis terhadap peningkatan mutu belajar pada mahasiswa terhadap pemilihan studi club dengan beberapa kriteria yang dapat diambil dari diri mahasiswa dengan penilaian terdiri dari Nilai matakuliah pendukung, nilai absensi matakuliah pendukung, nilai tes praktek dan minat. Dari berbagai kriteria yang dimiliki mahasiswa, dari ini dapat memberikan penentuan dalam pemilihan studi club sesuai dengan hasil dari nilai kriteria yang dimiliki oleh mahasiswa.
\end{abstract}

Kata kunci: Studi Clube, SPK, Stmik Royal, VIKOR, Mahasiswa.

(C) 2022 JIdT

\section{Pendahuluan}

Club belajar merupakan suatu konsep di mana club dianggap mampu untuk melakukan proses pembelajaran mandiri [1]. Tujuan adanya club belajar di dalam suatu instansi pendidikan biasanya ditujukan guna pengembangan kreativitas dan karir sesuai dengan kebutuhan khusus peserta club belajar [2]. Saat ini proses penentun studi club masih menggunakan cara manual sehingga membutuhkan waktu yang lama karena harus mencatat data nilai mahasiswa, minat dan juga kreativitas mahasiswa [3].

Evaluasi proses pembelajaran adalah proses untuk menentukan tingkat prestasi akademik mahasiswa secara menyeluruh dan berkesinambungan sesuai dengan ketentuan pendidikan [4]. Evaluasi pemilihan studi club dilakukan untuk mengukur keberhasilan prestasi belajar mahasiswa pada mata kuliah tertentu sesuai dengan program studi minat dan bakat mahasiswa [5]. Penelitian ini menentukan jurusan yang terbaik sesuai dengan nilai, rangking dan bakat siswa, sebagai upaya untuk memajukan prestasinya dimasa depan [6].

Menggunakan metode VIKOR sebagai pendukung keputusan secara objektif. Proses penentuan melibatkan banyak kriteria yang di nilai atau multikeriteria, maka dalam penyelesainya diperlukan sistem pendukung keputusan multikriteria [7]. Konsep dasar Metode VIKOR adalah menentukan ranking dari sampel-sampel yang ada dengan melihat hasil dari nilai-nilai utilitas dan regrets dari setiap sampel [8]. Sebagai sebuah aplikasi informasi, sistem pendukung

Diterima: 21-02-2021 | Revisi: 01-03-2022 | Diterbitkan: 31-03-2022| doi: 10.37034/jidt.v4i1.182 
keputusan dapat menyajikan informasi secara grafis [9]. VIKOR dapat menyusun banyak alternatif, sehingga dapat diasumsikan bahwa algoritma VIKOR masih relevan untuk digunakan dalam penelitian pemilihan studi club [10].

Metode VIKOR dihitung secara bertahap untuk memudahkan proses penentuan dan perhitungan untuk banyak kriteria [11]. Dengan metode vikor merupakan metode yang sangat memudahkan mahasiswa dalam menentukan studi club belajar [12]. Dengan Sistem Pendukung Keputusan dapat menghindari kesalahan dalam proses pemilihan studi club belajar sesuai dengan kriteria yang telah ditentukan serta dapat meningkatkan potensi dan kemampuan mahasiswa dalam proses pemilihan studi club [13].

\section{Metodologi Penelitian}

Pemilihan studi club dengan menggunakan metode vikor, dimana metode vikor adalah metode multikriteria yang digunakan dalam sistem, metode ini berfokus pada perangkingan dengan memilih dari satu set alternative[14]. Adapun kelemahan pada metode VIKOR adalah tidak adanya uji penentuan pada bobot kriteria, bobot kriteria dapat ditentukan dengan kebijakan dan keputusan seorang tertentu saja[15].

Kerangka kerja penelitian merupakan tahapan-tahapan yang dilakukan oleh penulis dalam menyelesaikan permasalahan yang akan dibahas. Kerangka kerja penelitian ini yang berhubungan dengan penentuan divisi studi club belajar. Kerangka kerja bertujuan untuk membahas tahapan pada penelitian ini yang dapat dilihat pada Gamabr 1.

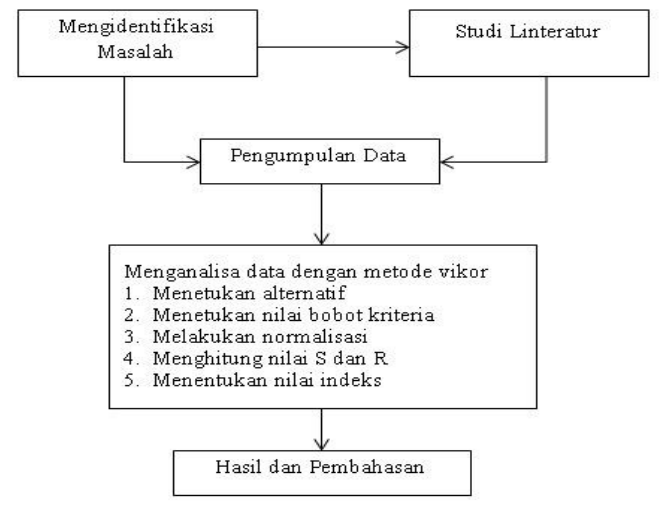

Gambar 1. Tahapan Penelitian,

\subsection{Mengidentifikasi Masalah}

Pada tahap ini penulis akan menemukan masalah yang terjadi pada kampus STMIK Royal Kisaran yaitu dalam menentukan studi club belajar agar dapat menyesuaikan dengan kemampuan kreatifitas dan minat mahasiswa. Dimana pihak kampus, mahasiswa masih melakukan pemilihan studi club belajar dalam memberikan kontribusi secara manual ataupun dengan kata lain hanya berdasarkan kemauan mahasiswa sendiri tanpa harus melihat nilai dari matakuliah pendukung serta minatnya, hal ini tentunya masih kurang efektif.

\subsection{Studi Linteratur}

Tahapan ini untuk mempelajari linteratur yang dapat ditentukan sesuai dengan pembahasan agar dapat dipergunakan dalam penelitian ini. Beberapa sumber dari linteratur yang didapatkan dari berbagai linteratur diantaranya jurnal, artikel, perpustakaan yang mengenai pembahasaan tentang Sistem Penduku Keputusan menggunakan metode VIKOR.

\subsection{Mengumpulkan Data.}

Pengumpulan data dapat dilakukan dengan cara mengumpulkan data-data mahasiswa berupa nilai matakuliah pendukung, nilai absensi, nilai tes praktek dan minat mahasiswa. Beberpa refrensi data yang bisa menunjang dalam menentukan pemilihan studi club. Diantaranya data-data yang akan perlukan.

\subsection{Menganalisa data dengan metode VIKOR.}

Menganalisa data menggunakan metode VIKOR, dengan melakukan analisis data mentah yang akan diproses dengan menggunakan metode VIKOR. Langkah-langkah metode ini.

a. Melakukan normalisasi yang disajikan pada Rumus (1).

$\mathrm{R}_{\mathrm{ij}}=\left(\frac{X_{j}^{+}-X_{i j}}{X_{j}^{+}-X_{j}^{-}}\right)$

Dimana i merupakan rumus alternatif. $\mathrm{j}$ adalah kriteria yang akan dijadikan acuan untuk menghitung nilai alternatif. $X_{i j}$ merupakan nilai dari matriks pengambilan keputusan. $\mathrm{X}^{+}$adalah nilai terbaik dalam satu kriteria dan $\mathrm{X}^{-}$adalah nilai terjelek dalam satu kriteria.

b. Cara menghitung nilai $\mathrm{S}$ dan $\mathrm{R}$ menggunakan Rumus (2) dan Rumus (3).

$\mathrm{S}_{\mathrm{i}}=\sum_{j=1}^{n} W j\left(\frac{X_{j}^{+}-X_{i j}}{X_{j}^{+}-X_{j}^{-}}\right)$

dan

$\mathrm{R}_{\mathrm{i}}=\operatorname{Max} \mathrm{j}\left[W_{j}\left(\frac{X_{j}^{+}-X_{i j}}{X_{j}^{+}-X_{j}^{-}}\right)\right]$

Dimanan $\mathrm{Wj}$ merupakan bobot dari masing-masing kriteria. Pada nilai S didapatkan dari nilai penjumlahan pada hasil perkalian bobot kriteria dengan mengunakan pada setiap data sampel.

c. Menentukan nilai indeks

Dimana menentukan nilai indeks dengan cara nilai $S$ dikurangi nilai $\mathrm{S}$ terkecil lalu dibagikan dengan nilai $\mathrm{S}$ terbesar dikurangi dengan nilai $\mathrm{S}$ terkecil dan dikali $\mathrm{v}$ dan dijumlahkan dengan nilai $\mathrm{R}$ dikurangi nilai $\mathrm{R}$ terkecil lalu dibagi dengan nilai $\mathrm{R}$ terbesar dikurangi nilai $\mathrm{R}$ terkecil dan dikali dengan 1 dikurangi $\mathrm{v}$ yang disajikan pada Rumus (4). 
$\mathrm{Q}_{\mathrm{i}}=\left[\frac{S_{i-S^{+}}}{S^{+}-S^{-}}\right] \mathrm{v}+\left[\frac{R_{i-R^{+}}}{R^{+}-R^{-}}\right](1-v)$

Dimana $\mathrm{Si}$ min merupakan nilai $\mathrm{S}$ terkecil. Si max adalah nilai $\mathrm{S}$ terbesar. $\mathrm{Ri}$ adalah nilai $\mathrm{R}$ terkecil sedangkan $\mathrm{Ri}$ max merupakan nilai $\mathrm{R}$ terbesar dan $\mathrm{v}$ adalah nilai yang sudah ditentukan dengan nilai 0.5 .

\section{d. Perangkingan alternatif}

Pada perangkingan merupakan hasil dari pengurutan nilai S, R dan Q. Mengusulkan alternatif peringkat terbaik berdasarkan mengukur indeks vikor dengan nilai Q minimum menjadi peringkat terbaik.

\section{Hasil dan Pembahasan}

Analasisa data merupakan penyelesaian dan mengindentifikasi permasalahan yang terjadi. Analisa masalah berupa data mahasiswa untuk menentukan bakat mahasiswa sesuai dengan studi club yang sudah ditentukan. Data kriteria penilaian dengan menggunakan metode VIKOR untuk menentukan pemilihan studi club guna untuk meningkatkan kualitas pembelajaran dan menghasilkan lulusan mahasiswa terbaik yang disajikan pada Tabel 1 .

Tabel 1. Data Alternatif

\begin{tabular}{ll}
\hline \multicolumn{1}{c}{ Alternatif (A) } & \multicolumn{1}{c}{ Keterangan } \\
\hline A1 & Ayu Anggraini \\
A2 & Aisa Nabila \\
A3 & Ade Febriyanti \\
A4 & Azri Siahaan \\
A5 & Dedi Setiawan \\
\hline
\end{tabular}

\section{Dimana:}

A1 adalah alternatif 1 dan keterangan dari alternatif 1 atas nama Ayu Anggraini yang disajikan pada Tabel 2.

Tabel 2. Data Kriteria

\begin{tabular}{ll}
\hline \multicolumn{1}{c}{ Kriteria $(\mathrm{K})$} & \multicolumn{1}{c}{ Keterangan } \\
\hline K1 & Nilai KHS \\
K2 & Nilai Absensi Matakuliah Pendukung \\
K3 & Nilai Tes Praktek \\
K4 & Minat \\
\hline
\end{tabular}

\section{Dimana:}

K1 itu adalah kriteria 1 yang berupa keterangan nilai absensi dari matakuliah pendukung yang disajikan pada Tabel 3 sampai dengan Tabel 7.

Tabel 3. Nilai Bobot

\begin{tabular}{cl}
\hline Nilai Bobot & \multicolumn{1}{c}{ Keterangan } \\
\hline 0,45 & Tidak Memuaskan / Tidak Minat (TM) \\
0,30 & Cukup Memuaskan (CM \\
0,20 & Memuaskan (M) \\
0,1 & Sangat Memuaskan / Minat (SM) \\
\hline
\end{tabular}

Tabel 4. Nilai Bobot untuk Kriteria Nilai Matakuliah Pendukung

\begin{tabular}{clr}
\hline $\mathrm{K} 1$ & \multicolumn{1}{c}{ Keterangan } & Bobot \\
\hline $0.00-1.00$ & Tidak Memuaskan & 0,45 \\
$1.01-2.00$ & Cukup Memuaskan & 0,30 \\
$2.01-3.00$ & Memuaskan & 0,20 \\
$3.01-4.00$ & Sangat Memuaskan & 0,1 \\
\hline
\end{tabular}

Tabel 5. Nilai Bobot untuk Kriteria Absensi Kehadiran dari Matakuliah Pendukung

\begin{tabular}{clc}
\hline $\mathrm{K})$ & Keterangan & Bobot \\
\hline$<=49.99 \%$ & Tidak Memuaskan & 0,45 \\
$50-69.99 \%$ & Cukup Memuaskan & 0,30 \\
$70-79.99 \%$ & Memuaskan & 0,20 \\
$>=80 \%$ & Sangat Memuaskan & 0,10 \\
\hline
\end{tabular}

Tabel 6 Nilai Bobot untuk Kriteria Nilai Tes Praktek

\begin{tabular}{clc}
\hline K3 & Keterangan & $\begin{array}{c}\text { Nilai } \\
\text { Bobot }\end{array}$ \\
\hline$<50$ & Tidak Memuaskan & 0,45 \\
$50-69.99$ & Cukup Memuaskan & 0,30 \\
$70-79.99$ & Memuaskan & 0,20 \\
$>=80$ & Sangat Memuaskan & 0,10 \\
\hline
\end{tabular}

Tabel 7. Nilai Bobot untuk Kriteria Minat

\begin{tabular}{lc}
\hline Kriteria $(\mathrm{K})$ & Keterangan \\
\hline Tidak Minat & 0,45 \\
Minat & 0,10 \\
\hline
\end{tabular}

Peneliti mengambil data club belajar sebagai contoh kasus untuk membuat Sistem Pendukung Keputusan pemilihan studi club belajar untuk mahasiswa di STMIK Royal Kisaran dengan metode VIKOR. Data yang diambil berdasarkan data nilai matakuliah pendukung, data absensi kehadiran matakuliah pendukung, data nilai tes praktek dan minat yang diambil berdasarkan dari pendaftaran mahasiswa. Kemudian data tersebut dihitung berdasarkan kriteria masing-masing menggunakan metode VIKOR.

a. Ranting kecocokan yang telah dibobotkan yang disajikan pada Tabel 8.

Tabel 8. Penilaian Alternatif Pada Setiap Kriteria

\begin{tabular}{lccccc}
\hline \multirow{2}{*}{ No } & Alternatif & \multicolumn{4}{c}{ Kriteria } \\
\cline { 3 - 6 } & & K1 & K2 & K3 & K4 \\
1 & A1 & 80 & 80 & 70 & 80 \\
2 & A2 & 80 & 80 & 80 & 50 \\
3 & A3 & 80 & 80 & 70 & 70 \\
4 & A4 & 70 & 80 & 80 & 50 \\
5 & A5 & 80 & 80 & 70 & 80 \\
\hline
\end{tabular}

b. Melakukan normalisasi nilai alternatif pada setiap kriteria.

Alternatif (A1), Kriteria (K1).

$\mathrm{R}_{11}=\frac{(80-80)}{(80-70)}=0$

Alternatif (A2), Kriteria (K1).

$\mathrm{R}_{12}=\frac{(80-80)}{(80-70)}=0$

Alternatif (A3), Kriteria (K1).

$\mathrm{R}_{13}=\frac{(80-80)}{(80-70)}=0$

Alternatif (A4), Kriteria (K1).

$\mathrm{R}_{14}=\frac{(80-70)}{(80-70)}=1$

Alternatif (A5), Kriteria (K1).

$\mathrm{R}_{15}=\frac{(80-80)}{(80-70)}=0$ 
Alternatif (A1), Kriteria (K2).

$\mathrm{R}_{21}=\frac{(80-80)}{(80-80)}=0$

Alternatif (A2), Kriteria (K2).

$\mathrm{R}_{22}=\frac{(80-80)}{(80-80)}=0$

Alternatif (A3), Kriteria (K2).

$\mathrm{R}_{23}=\frac{(80-80)}{(80-80)}=0$

Alternatif (A4), Kriteria (K2).

$\mathrm{R}_{21}=\frac{(80-80)}{(80-80)}=0$

Alternatif (A5), Kriteria (K2).

$\mathrm{R}_{21}=\frac{(80-80)}{(80-80)}=0$

Alternatif (A1), Kriteria (K3).

$\mathrm{R}_{31}=\frac{(80-70)}{(80-70)}=1$

Alternatif (A2), Kriteria (K3).

$\mathrm{R}_{32}=\frac{(80-80)}{(80-70)}=0$

Alternatif (A3), Kriteria (K3).

$\mathrm{R}_{33}=\frac{(80-70)}{(80-70)}=1$

Alternatif (A4), Kriteria (K3).

$\mathrm{R}_{34}=\frac{(80-80)}{(80-70)}=0$

Alternatif (A5), Kriteria (K3).

$\mathrm{R}_{35}=\frac{(80-70)}{(80-70)}=1$

Alternatif (A1), Kriteria (K4).

$\mathrm{R}_{41}=\frac{(80-80)}{(80-50)}=0$

Alternatif (A2), Kriteria (K4).

$\mathrm{R}_{42}=\frac{(80-50)}{(80-50)}=1$

Alternatif (A3), Kriteria (K4).

$\mathrm{R}_{43}=\frac{(80-70)}{(80-50)}=0$

Alternatif (A4), Kriteria (K4).

$\mathrm{R}_{44}=\frac{(80-50)}{(80-50)}=1$

Alternatif (A5), Kriteria (K4).

$\mathrm{R}_{45}=\frac{(80-80)}{(80-50)}=0$

c. Berikut adalah hasil dari normalisasi nilai alternatif pada setiap kriteriannya yang disajikan pada Tabel 9 .

Tabel 9 Normalisasi Nilai Alternatif

\begin{tabular}{cccccc}
\hline No & Alternatif & \multicolumn{4}{c}{ Kriteria } \\
\cline { 3 - 5 } & & K1 & K2 & K3 & K4 \\
1 & A1 & 0 & 0 & 1 & 0 \\
2 & A2 & 0 & 0 & 0 & 1 \\
3 & A3 & 0 & 0 & 1 & 0 \\
4 & A4 & 1 & 0 & 0 & 1 \\
5 & A5 & 0 & 0 & 1 & 0 \\
\hline
\end{tabular}

d. Normalisasi matriks dengan perkalian dengan bobot kriteria yang disajikan pada Tabel 10 .

Tabel 10. Normalisasi Perkalian Nilai Alternatif dengan Bobot

\begin{tabular}{cccccc}
\hline No & Alternatif & \multicolumn{4}{c}{ Kriteria } \\
\cline { 3 - 6 } & & $\mathrm{K} 1$ & $\mathrm{~K} 2$ & $\mathrm{~K} 3$ & $\mathrm{~K} 4$ \\
1 & $\mathrm{~A} 1$ & $0^{*} 0,1$ & $0^{*} 0,1$ & $1^{*} 0,20$ & $0 * 0,1$ \\
2 & $\mathrm{~A} 2$ & $0^{*} 0,1$ & $0 * 0,1$ & $0 * 0,1$ & $1 * 0,45$ \\
3 & $\mathrm{~A} 3$ & $0 * 0,1$ & $0 * 0,1$ & $1 * 0,20$ & $0 * 0,20$ \\
4 & $\mathrm{~A} 4$ & $1 * 0,20$ & $0 * 0,1$ & $0 * 0,1$ & $1 * 0,45$ \\
5 & $\mathrm{~A} 5$ & $0 * 0,1$ & $0 * 0,1$ & $1 * 0,20$ & $0 * 0,1$ \\
\hline
\end{tabular}

e. Hasil normalisasi nilai alternatif yang dilakukan dengan perkalian dengan $\mathrm{Wj}$ yang disajikan pada Tabel 11.

Tabel 11. Normalisasi Nilai dari Alternatif

\begin{tabular}{cccccc}
\hline \multirow{2}{*}{ No } & Alternatif & \multicolumn{4}{c}{ Kriteria } \\
\cline { 3 - 6 } & & K1 & K2 & K3 & K4 \\
\hline 1 & A1 & 0 & 0 & 0,20 & 0 \\
2 & A2 & 0 & 0 & 0 & 0,45 \\
3 & A3 & 0 & 0 & 0,20 & 0,20 \\
4 & A4 & 0,20 & 0 & 0 & 0,45 \\
5 & A5 & 0 & 0 & 0,20 & 0 \\
\hline
\end{tabular}

f. Menghitung nilai $\mathrm{S}$ dan $\mathrm{R}$ dari masing-masing alternatif

Nilai $A(A 1)=0+0+0,20+0=0,20$

Nilai $A(A 2)=0+0+0,20+0,45=0,45$

Nilai $A(A 3)=0+0+0,20+0,20=0,40$

Nilai $A(A 1)=0,20+0+0+0,45=0,60$

Nilai $A(A 1)=0+0+0,20+0=0,20$

g. Nilai $R$ yang tertinggi dari setiap alternatif berdasarkan kriteria.

$$
\begin{aligned}
& \mathrm{R}(\mathrm{A} 1)=0,20 \\
& \mathrm{R}(\mathrm{A} 2)=0,45 \\
& \mathrm{R}(\mathrm{A} 3)=0,20 \\
& \mathrm{R}(\mathrm{A} 4)=0,45 \\
& \mathrm{R}(\mathrm{A} 5)=0,20
\end{aligned}
$$

h. Nilai $\mathrm{S}$ dan $\mathrm{R}$ dari data alternatif yang disajikan pada Tabel 12.

Tabel 12. Nilai S dan R

\begin{tabular}{lcc}
\hline \multicolumn{1}{c}{ Alternatif } & Nilai S & Nilai R \\
\hline Ayu Anggraini & 0,20 & 0,20 \\
Aisa Nabila & 0,45 & 0,45 \\
Ade Febriyanti & 0,40 & 0,20 \\
Azri Siahaan & 0,60 & 0,45 \\
Dedi Setiawan & 0,20 & 0,20 \\
\hline
\end{tabular}

i. Terdapat masing-masing data adalah nilai terbesar dan nilai terkecil dari nilai $\mathrm{S}$ dan nilai $\mathrm{R}$. 
Menghitung nilai indeks

Nilai Q (A1)

$=\frac{(0,20-0,20)}{(0,60-0,20)} * 0,5+\frac{(0,20-0,20)}{(0,45-0,20)} *(1-0.5)$

$=(0 * 0.5)+(0 * 0.5)=0$

Nilai Q (A2)

$=\frac{(0,45-0,20)}{(0,60-0,20)} * 0.5+\frac{(0,45-0,20)}{(0,45-0,20)} *(1-0.5)$

$=(0.625 * 0.5)+(1 * 0.5)=0,812$

Nilai Q (A3)

$=\frac{(0,40-0,20)}{(0,60-0,20)} * 0.5+\frac{(0,20-0,20)}{(0,45-0,20)} *(1-0.5)$

$=(0.5 * 0.5)+(0 * 0.5)=0,25$

Nilai Q (A4)

$=\frac{(0,60-0,20)}{(0,60-0,20)} * 0.5+\frac{(0,45-0,20)}{(0,45-0,20)} *(1-0.5)$

$=(1 * 0.5)+(1 * 0.5)=1$

Nilai Q (A4)

$=\frac{(0,20-0,20)}{(0,60-0,20)} * 0.5+\frac{(0,20-0,20)}{(0,45-0,20)} *(1-0.5)$

$=(0 * 0.5)+(0 * 0.5)=0$

j. Dari hitungan diatas maka terdapat nilai indeks hasil dari perhitungan nilai peringkat indeks yang disajikan pada Tabel 13 dan Tabel 14.

Tabel 13. Sesuai dengan Minat

\begin{tabular}{lrl}
\hline \multicolumn{1}{c}{ Alternatif } & Nilai Q & \multicolumn{1}{c}{ Keterangan } \\
\hline Ayu Anggraini & 0,000 & Sesuai Minat \\
Aisa Nabila & 0,812 & Tidak Sesuai Minat \\
Ade Febriyanti & 0,250 & Sesuai Minat \\
Azri Siahaan & 1,000 & Tidak Sesuai Minat \\
Dedi Setiawan & 0,000 & Sesuai Minat \\
\hline
\end{tabular}

Tabel 14. Sesuai Minat yang dipilih Mahasiswa

\begin{tabular}{ll}
\hline Nilai Range & Matakuliah \\
\hline $0,00-0.50$ & Web Programming \\
$0.51-1,00$ & Desain Grafis \\
\hline
\end{tabular}

Berdasarkan nilai hasil akhir yang disajikan pada Tabel 12 yang diperoleh dari setiap prosesnya yang telah diproses menggunakan metode VIKOR, maka setiap nilai yang diperoleh oleh setiap alternatif akan mendapatkan hasil keputusan sesuai dengan minat. Dimana beberapa alternatif sudah mendapatkan hasil keputusan sesuai dengan minatnya.pada alternatif $\left(Q_{i}\right)$ Ayu Angraini adalah nilai $\mathrm{Q}_{0}$ sesuai minta dan Aisa Nabila nilai $\mathrm{Q}_{0,812}$ tidak sesuai minat.

\section{Kesimpulan}

Terdapat 4 kriteria untuk menentukan divisi studi club, yaitu Nilai Matakuliah Pendukung, Absensi Kehadiran Matakuliah Pendukung, Nilai Tes Praktek, dan Minat. Dengan menggunakan Sistem Pendukung Keputusan metode VIKOR dapat ditentukan dari nilai bobot dan dari nilai masing-masing kriteria untuk selanjutnya akan diproses dalam sistem. Dengan menerapkan metode VIKOR untuk pemilihan studi club, terdapat banyaknya mahasiswa yang memilih studi club belajar berdasarkan minat, sehingga tidak sesuai dengan yang disarankan dalam sistem. Dengan menerapkan perhitungan dengan menggunakan metode VIKOR untuk menentukan studi club, didapatlah hasil dari nilai akurasi $100 \%$, di mana hasil perhitungan manual sama dengan perhitungan sistem, yaitu tidak memiliki selisih dan menghasilkan keputusan yang sama.

\section{Daftar Rujukan}

[1]. A. P. Wibawa, J. A. Fauzi, S. Isbiyantoro, R. Irsyada, Dhaniyar, and L. Hernández, "VIKOR multi-criteria decision making with AHP reliable weighting for article acceptance recommendation," Int. J. Adv. Intell. Informatics, vol. 5, no. 2, pp. 160-168, 2019, doi: 10.26555/ijain.v5i2.172.

[2]. A. Garg, S. Das, J. Maiti, and S. K. Pal, "Granulized Z-VIKOR model for failure mode and effect analysis," IEEE Trans. Fuzzy Syst., vol. 6706, no. c, 2020, doi: 10.1109/TFUZZ.2020.3037933.

[3]. M. Nur and S. Susliansyah, "Penerapan Sistem Pendukung Keputusan Pemilihan Jurusan Dengan Metode Vikor Pada Smk Pariwisata Depok," J. Techno Nusa Mandiri, vol. 16, no. 2, pp. 127-132, 2019, doi: 10.33480/techno.v16i2.751.

[4]. M. FAUZI, M. RIDWAN, and K. KHALID, "Kombinasi Metode AHP dan VIKOR Untuk Pemilihan Santri Berprestasi," Matics, vol. 12, no. 1, p. 28, 2020, doi: 10.18860/mat.v12i1.8270.

[5]. T. Arslan, "A psychometric approach to the VIKOR method for eliciting subjective public assessments," IEEE Access, vol. $8, \quad$ pp. 54100-54109, 2020, doi: 10.1109/ACCESS.2020.2981424.

[6]. R. A. Purba, . Ambiyar, and U. Verawardina, "Deteksi Mahasiswa Yang Dapat Menyusun Tugas Akhir dengan Metode Visekriterijumsko Kompromisno Rangiranje (VIKOR)," Techno.Com, vol. 20, no. 2, pp. 210-220, 2021, doi: $10.33633 /$ tc.v20i2.4360.

[7]. E. Rafieyan, R. Khorsand, and M. Ramezanpour, "An adaptive scheduling approach based on integrated best-worst and VIKOR for cloud computing," Comput. Ind. Eng., vol. 140, p. 106272, 2020, doi: 10.1016/j.cie.2020.106272.

[8]. Y. Primadasa and H. Juliansa, "Penerapan Metode Vikor dalam Seleksi Penerimaan Bonus Pada Salesman Indihome," Digit. Zo. J. Teknol. Inf. dan Komun., vol. 10, no. 1, pp. 33-43, 2019, doi: 10.31849/digitalzone.v10i1.2228.

[9]. Mesran, K. Ulfa, D. P. Utomo, and I. R. Nasution, "Penerapan Metode VlseKriterijumska Optimizacija I Kompromisno Resenje ( Vikor ) Dalam Pengangkatan Guru," Algoritm. J. Ilmu Komput. dan Inform., vol. 4, no. 1, pp. 265-271, 2020.

[10]. C. M. Sari, S. D. Nasution, and R. D. Sianturi, "Sistem Pendukung Keputusan Seleksi Pemilihan Ajang Service Ambassador Medan Menerapkan Metode VIKOR (Studi Kasus: Pt. Midi Utama Indonesia Tbk)," J. Sist. Komput. dan Inform., vol. 1, no. 3, p. 182, 2020, doi: 10.30865/json.v1i3.2093.

[11]. D. S. P. Sinaga, S. R. Andani, and D. Suhendro, "Analisis Pemilihan Guru Konseling dengan Metode VIKOR pada SMK TPI Alhasanah Pematang Bandar," J. Comput. Syst. Informatics, vol. 3, no. 1, pp. 9-15, 2021, doi: 10.47065/josyc.v3i1.951.

[12]. D. N. Batubara, A. P. Windarto, and ..., "Analisis Metode VIKOR Pada Pemilihan Sabun Cuci Tangan Terbaik Berdasarkan Konsumen," Komik ..., vol. 4, pp. 52-57, 2020, 
doi: 10.30865/komik.v4i1.2586.

[13]. T. Murti et al., "Pemilihan Mie Terlaris Pada Toko Aisyah dengan Metode VIKOR ( VIšekriterijumsko Ko mpromisno Rangiranje )," J. Golden Age, vol. 9, no. 115, pp. 9-15, 2020.

[14]. A. Nasution and K. Ulfa, "Sistem Pendukung Keputusan Kelayakan Pemberian Asuransi Jiwa Untuk Nelayan dengan
Menggunakan Metode Vikor (Studi Kasus: Dinas Kelautan dan Perikanan Medan)," J. Sist. Komput. dan Inform., vol. 1, no. 3, p. 220, 2020, doi: 10.30865/json.v1i3.2162.

[15]. U. Hasanah and C. Latiffani, "International Conference on Social, Sciences and Information Technology," vol. 4509, no. 1, pp. 1-7, 2020 